\title{
Analysis of air jet Erosion on Duplex Stainless Steel
}

\author{
Roshan Kuruvila, S. Thirumalai Kumaran, M. Adam Khan
}

\begin{abstract}
The prevention or minimization of erosion is an urgent need. The proper selection of the material and the adopting methods for controlling the factors influencing erosion are the commonly used techniques. Duplex Stainless Steel because of its good corrosion resistance and other properties becomes a common choice. To have an effective control over erosion we must understand the effect of each parameter over the rate of erosion. Air jet test rig was used to study the erosion behavior of Duplex Stainless steel of 2205 grade in a controlled environment. Erosion tests were carried out with varying angle of impact, flow velocity and mass flow rate under standard conditions using an air jet erosion rig made according to ASTM G76 standard. Examination of the results associated with various elements such as impact angles, mass flow rate and flow velocity. The results showed that the erosion rate was maximum at lower impact angles and decreases with higher impact angles and the erosion rate increase with an increase in velocity and decrease with the increase in mass flow rate.
\end{abstract}

Keywords : duplex steel, erosion, standard.

\section{INTRODUCTION}

$\mathrm{O}$ 1 and gases for the industrial applications are to be transported from one place to another using pipe lines using complex designs [1]. These pipelines are subjected to continuous impingement of solid particles present in the flow. These continuous impacts causes material loses over the surface by the phenomenon known as erosion. The material loss due to the solid particle erosion is supposed to be a series factor in extensive damage resulting in the high material loss and maintenance costs [2,3]. Therefore, the selection of materials for the pipeline is so critical that it has to withstand high pressure and adverse environmental conditions. Duplex Stainless Steels (DSSs) possess a good combination of toughness, strength and corrosion resistance suited for large variety of applications such nuclear power plants, pipeline industries and chemical industries etc. [4, 5]. A wide grade of DSSs ranging from lean to super have been developed according to the various industrial demands. Duplex 2205 is a two-phase, ferritic, austenitic alloyed stainless steel having high yield strength fatigue strength, outstanding resistance to corrosion and erosion in severe environment al conditions was selected for the study. The present work scientifically

Revised Manuscript Received on December 30, 2019.

* Correspondence Author

Roshan Kuruvila, Department of Automobile Engineering, Kalasalingam Academy of Research and Education, Krishnankoil-626126, India. Email: roskur69@gmail.com

S. Thirumalai Kumaran*, Faculty of Mechanical Engineering, India. Email: thirumalaikumaran@yahoo.com

M. Adam Khan, Department of Mechanical and Industrial Engineering Technology, University of Johannesburg, Johannesburg, South Africa. Email: adamkhanm@gmail.com Kalasalingam Academy of Research and Education, Krishnankoil-626126,

evaluated the erosion rate of DSS 2205 at room temperature by varying the impact velocity, angle and mass flow rate using an air-jet erosion test rig. The results can be effectively used to investigate the importance of critical factors of erosion mechanisms of DSS2205 at different flow velocities and impact angles, which can be properly used to control the failures.

\section{EXPERIMENTAL PROCEDURE}

\section{A. Material}

The DSS 2205 steel specimens with almost same proportions austenitic and ferritic structure of square shape having $25 \times 25 \mathrm{~mm}$ size and $5 \mathrm{~mm}$ thickness were used in the tests. Prior to each test, the steel specimens were cut to shape using waterjet abrasive cutting machine. Surface was not polished to maintain the surface roughness. The chemical composition of the DSS 2205 steel is shown in Table I.

\section{B. Experiments and Methods}

The air jet erosion test rig, Ducom made TR470 is used to conduct the erosion study. Alumina particles having a mesh size of 50 microns were used as the erodent material. The various operating parameters and levels are shown in Table II.

The erosion rate measured in grams/ minute is obtained by controlling the machining parameters likely: impact angle, velocity and discharge rate of alumina at a constant for a specific period of 30 minutes. The loss of material was determined and the weight measurement was performed using a precision electronic balance of accuracy $\pm 0.01 \mathrm{mg}$. The erosion rate was calculated using the equation Erosion rate $=$ $(\mathrm{Wb}-\mathrm{Wa}) / \mathrm{T}[6]$, where $\mathrm{Wb}$ and $\mathrm{Wa}$ are weights before and after erosion. $\mathrm{T}$ is the time in minutes. A properly designed erosion test rig which is capable of capable of producing erosive situations over a range parameter was selected. The compressed air mixed with abrasive particles having steady flow rate is made to impinge over the surface under a controlled environment at room temperature. The parameters such as feed rate, and the impact velocities are controlled by the pressure of the compressed air [7]. The output, erosion rate in grams/ minute is controlled by the parameters such as impact angle, velocity, and mass flow rate of abrasives for a time of 30 minutes [8].

\section{RESULTS AND DISCUSSION}

The summary of the results after experimentation is shown in Table III. Figure 1 shows the erosion rates vs. particle speed at various impact angles. 


\section{Analysis of air jet Erosion on Duplex Stainless Steel}

Erosion rates were calculated on the weight loss and the time at different impact angle at constant mass flow rate whereas Figure 2 shows erosion rate vs. mass flow rate at various angle of impact with constant flow velocity. From Figure 1 clearly shows that the particle speed and impact have a greater influence on the material removal rate. The different combinations of velocity and impact angles have different types of erosion mechanisms. From Figure 2, the increase in mass flow results in decrease of material removal rate. This is also due to the influence of various erosion mechanisms.

Table- I: Element Composition of DSS 2205

\begin{tabular}{|l|l|} 
Elements & wt. \% \\
\hline $\mathrm{Cr}$ & 22.75 \\
\hline $\mathrm{Ni}$ & 5.864 \\
\hline $\mathrm{Mn}$ & 1.423 \\
\hline $\mathrm{Si}$ & 0.503 \\
\hline $\mathrm{P}$ & 0.026 \\
\hline $\mathrm{S}$ & 0.015 \\
\hline $\mathrm{C}$ & 0.018 \\
\hline $\mathrm{Mo}$ & 3.215 \\
\hline $\mathrm{Fe}$ & 65.6 \\
\hline $\mathrm{Al}$ & 0.046 \\
\hline $\mathrm{Ti}$ & 0.011 \\
\hline $\mathrm{V}$ & 0.012 \\
\hline $\mathrm{Co}$ & 0.02 \\
\hline
\end{tabular}

Table- II: Experimental Parameters

Machining Parameters

\begin{tabular}{|c|c|c|c|}
\hline $\begin{array}{l}\text { Impact Angle } \\
\text { Flow velocity } \\
(\mathrm{m} / \mathrm{s})\end{array}$ & $\begin{array}{l}30^{0} \\
150-200\end{array}$ & $\begin{array}{l}45^{0} \\
150-200\end{array}$ & $\begin{array}{l}90^{0} \\
150-200\end{array}$ \\
\hline $\begin{array}{l}\text { Mass flow rate } \\
(\mathrm{gm} / \mathrm{m})\end{array}$ & $2.5-5$ & $2.5-5$ & $2.5-5$ \\
\hline Time (min) & 30 & 30 & 30 \\
\hline
\end{tabular}

The erosion rate is maximum at higher at higher flow velocity and low impact angles whereas minimum at lower particle speeds and higher impact angles. The increase in the flow velocity results in the increase of the kinetic energy of the abrasive particles and lower the impact angles the contact surface will be more localized thereby causing more material removal. At lower impact angles the material loss is mainly due to plastic deformation caused by the micro forging whereas the increase in velocity causes ploughing mechanism.

Table- III: Experimental Results

\begin{tabular}{|l|l|l|l|l|}
\hline Velocity of & Mass flow & \multicolumn{4}{|c|}{ Angle of impact (deg) } \\
\cline { 3 - 5 } Flow $(\mathrm{m} / \mathrm{s})$ & rate $(\mathrm{gm} / \mathrm{m})$ & $30^{\circ}$ & $45^{\circ}$ & $90^{\circ}$ \\
\hline 125 & 2.5 & 1.67 & 1.30 & 1.22 \\
\hline 125 & 3.75 & 1.39 & 1.11 & 1.04 \\
\hline 125 & 5 & 1.12 & 0.93 & 0.87 \\
\hline 175 & 2.5 & 2.33 & 1.82 & 1.70 \\
\hline 175 & 3.75 & 1.89 & 1.56 & 1.46 \\
\hline 175 & 5 & 1.45 & 1.30 & 1.21 \\
\hline 225 & 2.5 & 3.00 & 2.34 & 2.19 \\
\hline 225 & 3.75 & 2.51 & 2.00 & 1.88 \\
\hline 225 & 5 & 2.01 & 1.67 & 1.56 \\
\hline
\end{tabular}

At lower velocity and higher Impact angles only a limited amount particle attains the greater momentum and higher impact angle the contact area is more thereby the amount of material removal will be limited and also at this condition the deformation is mainly due to elastic deformation. From Figure 2, the increase in the mass flow rate reduces the erosion rate. The increase in mass flow rate means more quantity of abrasive particles flowing through the nozzle on to the surface. The increase in the number of particles causes rebound and deviation in the trajectory forcing the particles to sliding over the surface without making any erosion.

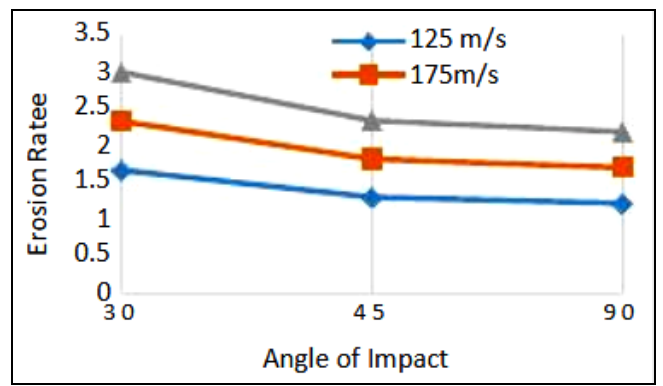

Fig. 1.Constant mass flow rate

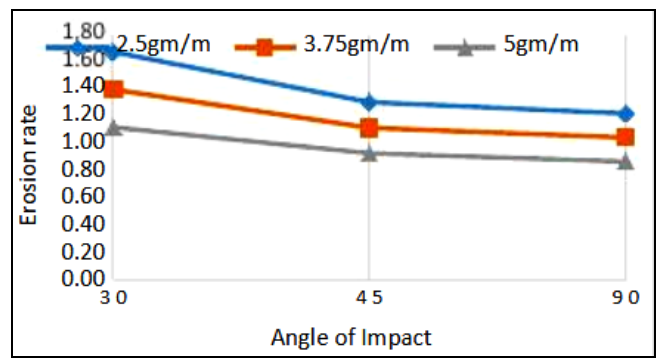

Fig. 2.Constant flow velocity

\section{CONCLUSIONS}

- The various critical parameters affecting the erosion rate have been identified. Impact velocity, impingement angle are found to be significant for minimizing the erosion rate.

- The erosion rate increased with increasing particle speed for all the impact angles and the maximum erosion rate was at higher particle velocity and lower impact angles due to due to plastic deformation dominated at higher impact angles whereas micro cutting prevails at lower angles.

- The results indicated that the mass flow rate had little influence on the erosion rate at all impact angles.

\section{REFERENCES}

1. H. Najibi, R. Rezaei, J. Javanmardi, Kh. Nasrifar, and M. Moshfeghian, "Economic evaluation of natural gas transportation from Iran's South-Pars gas field to market," Applied Thermal Engineering, vol. 29, 2009, pp. 2009-2015.

2. J. Postlethwaite, M. H. Dobbin, and K. Bergevin, "The role of oxygen mass transfer in the erosion-corrosion of slurry pipelines," Corrosion, vol. 42, 1986, pp. 514-521.

3. I. Finnie, "Erosion of surfaces by solid particles," Wear, vol. 3, 1960, pp. 87-103.

4. Y. Guo, J. Hu, J. Li, L. Jiang, T. Liu, and Y. Wu, "Effect of annealing temperature on the mechanical and corrosion behavior of a newly developed novel lean duplex stainless steel," Materials, vol. 7, 2014, pp. 6604-6619.

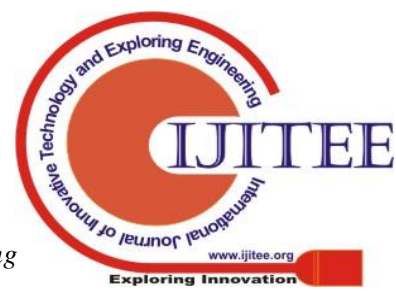


5. I. Utu, I. Mitelea, S. Urlan, and C. Crăciunescu, "Transformation and precipitation reactions by metal active gas pulsed welded joints from X2CrNiMoN22-5-3 duplex stainless steels," Materials, vol. 9, 2016, pp. 606

6. A. Viswanath, H. Dieringa, K.K. Ajith Kumar, UTS. Pillai, B.C. Pai, "Investigation on mechanical properties and creep behavior of stir cast AZ91-SiCp composites," Journal of Magnesium and Alloys, vol. 3, 2015, pp. 16-22.

7. Mayank Patela, Darshan Patela, S. Sekar, P.B. Tailora, and P.V. Ramanaa, "Study of solid particle erosion behaviour of SS 304 at room temperature," Procedia Technology, vol. 23, 2016, pp. 288-295.

8. K. Balamurugan, M. Uthayakumar, M. Ramakrishna, UTS. Pillai, “Air jet erosion studies on $\mathrm{Mg} / \mathrm{SiC}$ composite," Silicon, 2019, pp $1-11$.

\section{AUTHORS PROFILE}

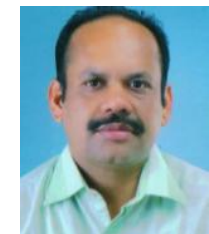

Roshan Kuruvila is a Research Scholar at Department of Automobile Engineering in Kalasalingam Academy of Research and Education, Krishnankoil. Currently he is working as Assistant Professor in Amal Jyothi College of Engineering, Kerala.

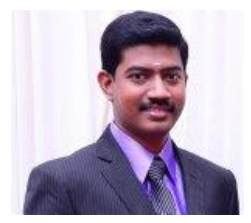

S. Thirumalai Kumaran completed his Ph.D degree in Mechanical Engineering from Kalasalingam Academy of Research and Education (KARE), India, in 2015. After completing Ph.D., he worked as an Assistant Professor at School of Mechanical Engineering, Yeungnam University, South Korea for a period of one year. He is currently an Associate Professor at School of Automotive and Mechanical Engineering, KARE

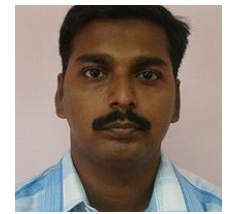

M. Adam Khan completed his Ph.D. degree in Mechanical Engineering from National Institute of Technology, Trichy. Currently he is working as a post-doctoral fellow in University of Johannesburg, South Africa. His area of interest includes coating, high temperature corrosion and machining of composites. 